\title{
MR Neurography of Greater Occipital Nerve Neuropathy: Initial Experience in Patients with Migraine
}

\author{
(D) L. Hwang, (DR. Dessouky, (D). Xi, (D)B. Amirlak, and (D) A. Chhabra
}

\begin{abstract}
BACKGROUND AND PURPOSE: MR imaging of peripheral nerves (MR neurography) allows improved assessment of nerve anatomy and pathology. The objective of this study was to evaluate patients with unilateral occipital neuralgia using MR neurography and to assess the differences in greater occipital nerve signal and size between the symptomatic and asymptomatic sides.
\end{abstract}

MATERIALS AND METHODS: In this case-control evaluation using MR neurography, bilateral greater occipital nerve caliber, signal intensity, signal-to-noise ratios, and contrast-to-noise ratios were determined by 2 observers.

RESULTS: Among 18 subjects with unilateral occipital migraines, the average greater occipital nerve diameter for the symptomatic side was significantly greater at $1.77 \pm 0.4 \mathrm{~mm}$ than for the asymptomatic side at $1.29 \pm 0.25 \mathrm{~mm}(P=.001)$. The difference in nerve signal intensity between the symptomatic and asymptomatic sides was statistically significant at $269.06 \pm 170.93$ and $222.44 \pm$ 170.46, respectively $(P=.043)$. The signal-to-noise ratios on the symptomatic side were higher at $15.79 \pm 4.59$ compared with the asymptomatic nerve at $14.02 \pm 5.23(P=.009)$. Contrast-to-noise ratios were significantly higher on the symptomatic side than on the asymptomatic side at $2.57 \pm 4.89$ and $-1.26 \pm 5.02$, respectively $(P=.004)$. Intraobserver performance was good to excellent (intraclass coefficient correlation, $0.68-0.93$ ), and interobserver performance was fair to excellent (intraclass coefficient correlation, $0.54-0.81)$.

CONCLUSIONS: MR neurography can be reliably used for the diagnosis of greater occipital nerve neuropathy in patients with unilateral occipital migraines with a good correlation of imaging findings to the clinical presentation.

ABBREVIATIONS: Botox = onobotulinumtoxin A; $\mathrm{CNR}=$ contrast-to-noise ratio; $\mathrm{GON}=$ greater occipital nerve; $\mathrm{ICC}=$ intraclass correlation coefficient; $\mathrm{MRN}=$ MR neurography; PSIF = reversed fast imaging with steady-state precession

M igraine is a common debilitating neurovascular disorder. Thirty-five million Americans, women more than men, have migraines leading to substantial pain and medical costs of $\$ 1$ billion yearly. ${ }^{1-5}$ The exact pathogenesis of migraines is debated between a more popular central theory of cortical spreading depression and neuronal hyperexcitability ${ }^{6}$ versus an extracranial pathology with compression and/or irritation of peripheral branches of the trigeminal and occipital nerves. The latter is hypothesized to result in triggered release of inflammatory and nociceptive peptides, which reach the meninges, inducing meningeal nociception and migraine. ${ }^{6-10}$ A number of conservative and

Received March 15, 2017; accepted after revision June 14.

From the Departments of Plastic Surgery (L.H., B.A.) and Radiology (R.D., Y.X., A.C.) University of Texas Southwestern Medical Center, Dallas, Texas; and Department of Radiology (R.D.), Faculty of Medicine, Zagazig University, Zagazig, Egypt.

Please address correspondence to Avneesh Chhabra, MD, Musculoskeletal Radiology, UT Southwestern Medical Center, 5323 Harry Hines Blvd, Dallas, TX 75390-

9178; e-mail: avneesh.chhabra@utsouthwestern.edu

http://dx.doi.org/10.3174/ajnr.A5354 surgical peripheral nerve treatments have been reported for peripheral neuropathy (eg, perineural injections of steroids or onobotulinumtoxin A [Botox], radiofrequency ablation, and surgical decompression). ${ }^{11-29}$ The greater occipital nerve (GON) is a sensory branch that arises from the dorsal ramus of the second cervical spinal nerve, ${ }^{30}$ and its compression has been proposed as the etiology of clinically manifested occipital migraines. ${ }^{18}$ Currently, the diagnosis is established on the basis of a combination of clinical history of posterior head and neck pain, tenderness on physical examination limited to the occipital area, and, in some cases, response to perineural injections. ${ }^{31}$

MR neurography (MRN) is a multiplanar nerve-selective imaging used to evaluate peripheral nerve anatomy and pathology. ${ }^{32}$ MRN has been successfully used in brachial plexopathies and has been shown to affect clinical diagnosis and management. ${ }^{33-35}$ In particular, 3D reversed fast imaging with steady-state precession (3D PSIF) has been shown to selectively identify small peripheral nerves around the head and neck region due to suppression of perineural fat and vascular signal. ${ }^{36,37}$ This is an isotropic se- 

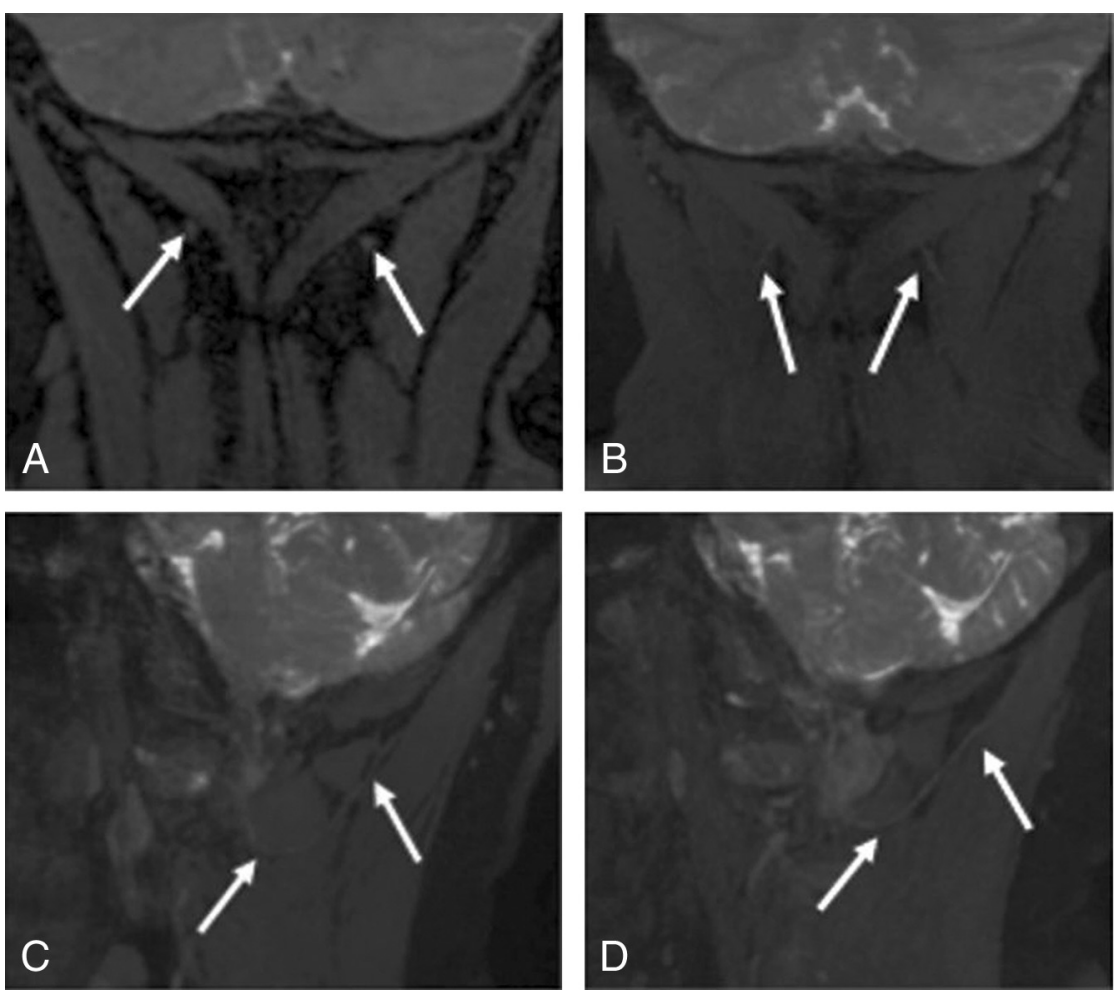

FIG 1. 3T MRN demonstrating a normal GON. A, Coronal 3D PSIF shows bilateral GONs (arrows). $B$, Eight-millimeter-thick MIP reconstruction in the coronal plane shows the normal GONs (arrows). $C$ and $D$, Eight-millimeter-thick isotropic MIP reconstruction in the sagittal plane shows right and left GONs (arrows).

quence, which can be obtained in sub-1-mm resolution and provides a high signal-to-noise ratio and soft-tissue contrast. Normal nerves on 3D DWI-PSIF appear isointense to muscle, while nerve entrapment and resultant neuropathy are demonstrated by an increase in size and signal intensity proximal to the entrapment. ${ }^{38,39}$ There have been no reports of quantitative evaluation of the GON signal and contrast characteristics in patients with occipital neuralgia (migraine), to our knowledge. Classically, the SNR has been defined as a measure comparing the level of a desired signal with the level of background noise of the image. ${ }^{40,41}$ The contrast-to-noise ratio (CNR) is defined as the difference in SNR between 2 relevant tissue types ${ }^{42}$ (ie, the nerve in question [GON] and the adjoining muscle [semispinalis capitis]).

The aim of this study was to evaluate patients with clinically suspected unilateral occipital neuralgia with MRN and assess the differences in GON signal and size characteristics between the symptomatic and asymptomatic sides. Our hypothesis was that the symptomatic side GON will be different (brighter and thicker) than the one on the asymptomatic side. In addition, inter- and intraobserver performance was evaluated.

\section{MATERIALS AND METHODS \\ Patient Population}

This is a Health Insurance Portability and Accountability Actcompliant, institutional review board-approved retrospective cross-sectional study. Informed consent was waived. A consecutive series of patients underwent occipital nerve MRN with the primary diagnosis of chronic unilateral occipital neuralgia from 2014 to 2016 at our institution. The patients were referred as a convenience sample from the plastic surgery clinic. Patient demographic factors were recorded, including age, sex, and clinical characteristics of their migraines, including laterality of pain, frequency, duration, intensity (on a qualitative scale from 1 to 10 ), subjective triggers, and occipital tenderness on physical examination. Possible predisposing factors to migraines such as family history of migraines, previous head trauma, and comorbidities were recorded. Previous methods of treatment including Botox, nerve block, radiofrequency ablation, and an operation were recorded as well as any previous head and neck imaging for comparison. Patients were excluded from this study if they were unable to localize their pain to one side or unable to quantify the difference in pain between the 2 sides (ie, zero versus reduced pain on the contralateral side). The subsequent treatment and outcomes are the subject of another study and article. This study was limited to evaluating nerve characteristic differences among the symptomatic-versusasymptomatic GONs.

\section{Image Aquisition and GON Analysis}

Occipital MRN from the level of the base of the skull to the C5-6 area was performed, encompassing bilateral GONs in all 18 patients who met the criteria for possible GON compression based on history and physical examination, as described above. 3D coronal PSIF imaging was performed in all cases on high-field MR imaging scanners (Avanto, 1.5T, Siemens, Erlangen, Germany; and Achieva, 3T, Philips Healthcare, Best, the Netherlands). The parameters included $\mathrm{TR}=12 \mathrm{~ms}, \mathrm{TE}=3 \mathrm{~ms}$, voxel size $=0.9$ $\mathrm{mm}$, isotropic, fat suppression $=$ water-selective. Eight-millimeter-thick-slab maximum intensity projections were obtained, which displayed the nerve in multiple planes (Fig 1 shows the normal nerve from an asymptomatic subject for comparison). The GON was visualized in all cases on both sides exiting from the cervical spine and coursing toward and lateral to the occipital protuberance. Two trained, experienced radiologists measured the signal and transverse diameter of the GON and semispinalis capitis, regardless of the affected side and blinded to the laterality of symptoms (Figs 2 and 3). The first observer (reader 1) had 7 years of experience interpreting MRN scans, while the second observer (reader 2) had 1 year of experience. The time between the first and second data collections of reader 1 spanned approximately 4 months. The GON signal and size were measured on the coronal image, midway between the spinal foramen and the point where it courses under the semispinalis capitis muscle. The largest diameter or most hyperintense T2 signal persisting on at least two 0.9-mm sections was measured. The freehand ROI tool on Intellispace PACS (Isite; Philips Healthcare) was used to include the 

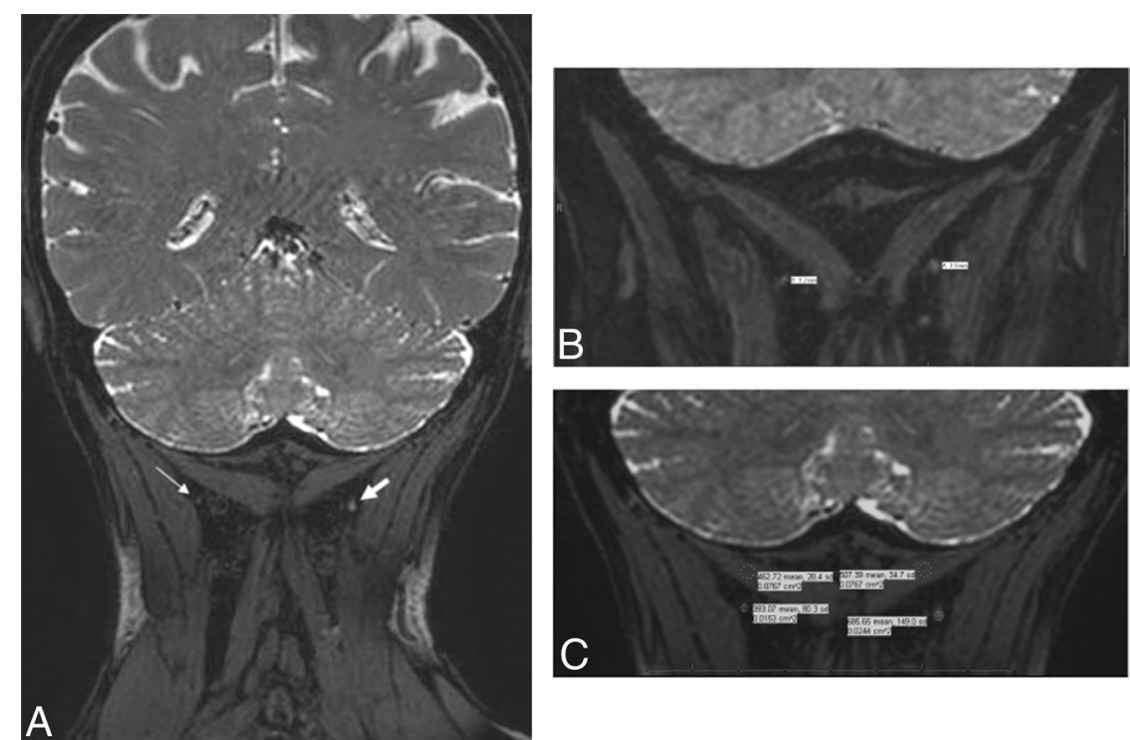

FIG 2. 3D Coronal PSIF images at $3 T$. A. Enlarged, hyperintense left greater occipital nerve (in comparison with the right). $B$, Caliber measurements show a larger left occipital nerve $(1.6 \mathrm{~mm})$ compared with the right $(1.2 \mathrm{~mm})$. C, Signal intensity measurements for both greater occipital nerves and semispinalis capitis muscles.
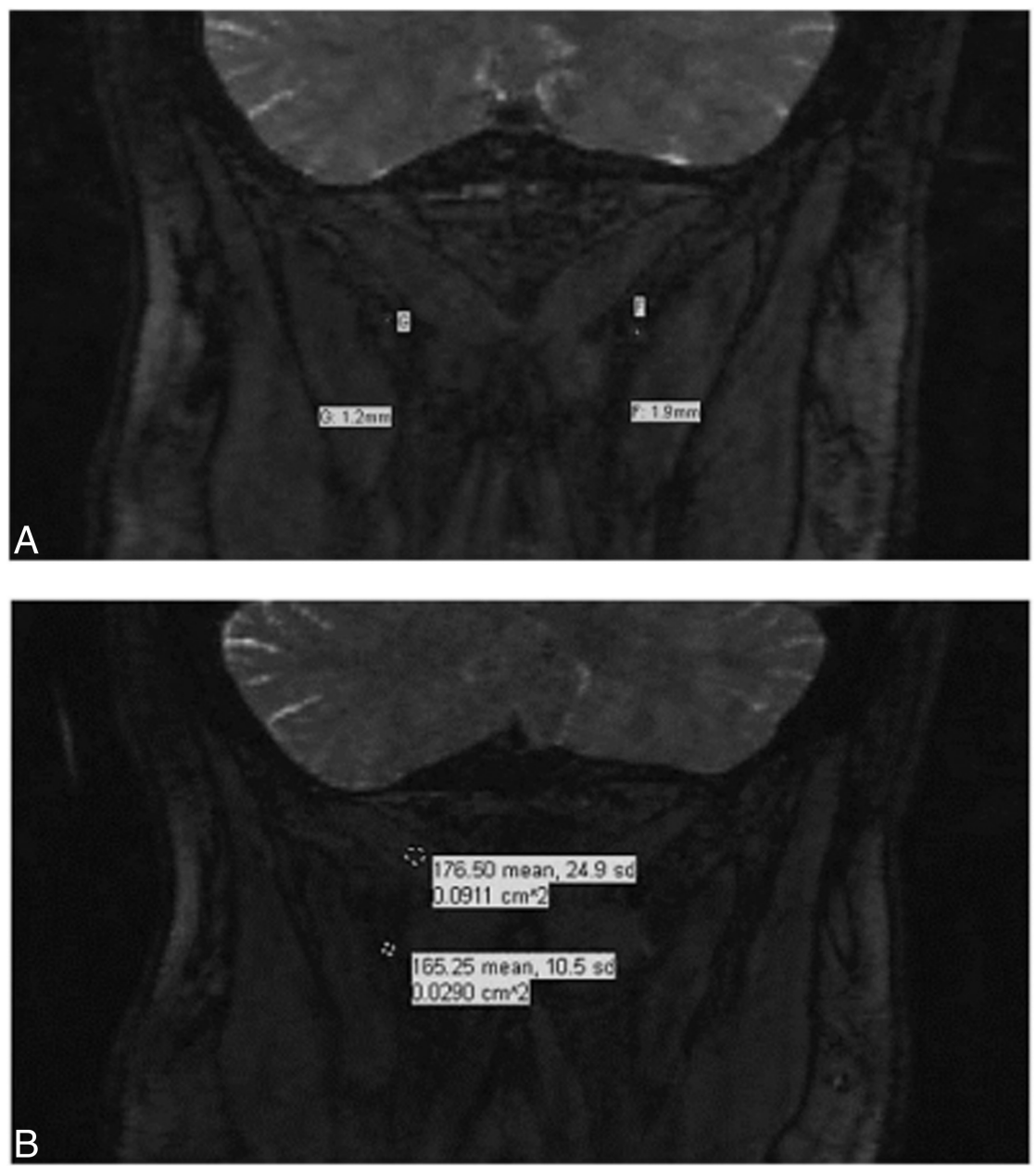

FIG 3. Coronal 3D PSIF images at 1.5T. $A$, Caliber measurements for the right and left GONs. $B$, Signal intensity measurements for the right GONs and semispinalis capitis muscles.
GON while excluding any extraneous soft tissues, such as fat or muscle. A 10-mm circular ROI was used for muscle signal measurement.

For each case, the control group consisted of nerve measurements obtained from the asymptomatic side, whereas the subject group included nerve measurements from the symptomatic side. After we obtained nerve diameter and signal intensity for both symptomatic and asymptomatic GONs, the T2 signal-to-noise ratio $\left[\mathrm{SNR}=\mathrm{SI}_{\text {nerve }} /\right.$ $\left.\left(\mathrm{SI}_{\text {nerve }}\right)^{1 / 2}\right]$ and the contrast-to-noise ratio $\left[\mathrm{CNR}=\left(\mathrm{SI}_{\text {nerve }}-\mathrm{SI}_{\text {muscle }}\right) /\left(\mathrm{SI}_{\text {nerve }}\right)^{1 / 2}\right]$ were calculated for each nerve in both groups. All data points, measurements, and calculations were recorded on an Excel spreadsheet (Microsoft, Redmond, Washington) for data analysis.

\section{Statistical Analysis}

Descriptive statistics were used for GON diameter, signal intensity, SNR, and CNR measurements on MRN. Differences in subject-versus-control groups were tested with a paired $t$ test at .05 . Interobserver performance was assessed with intraclass correlation coefficients (ICCs). Agreement was classified as excellent (0.75-1.0), good (0.60-0.74), fair (0.40-0.59), and poor $(<0.40) .{ }^{43}$ Furthermore, to evaluate whether a correlation existed between the duration of migraine symptoms from onset to MR imaging acquisition and MRN findings such as GON caliber and signal, we determined the Spearman rank correlation coefficients. A confidence interval of 95\% was used throughout this study. R statistical and computing software, Version 3.3.2 (http://www.r-project.org) and SAS 9.4 (SAS Institute, Cary, North Carolina) were used for statistical analysis.

\section{RESULTS}

There were 18 patients with persistent chronic unilateral occipital migraine histories (Table 1) who underwent a broad spectrum of treatment options (Table 2) before MRN acquisition. Seven $(39 \%)$ patients were imaged on a 3T MRN scanner versus 11 (61\%) patients imaged on a $1.5 \mathrm{~T}$ MRN scanner. None of the patients had a known central brain, neck, or spinal mass lesion. Prior outside imaging (performed in 6 of 18 patients) included CT/MR imag- 
Table 1: Patient demographic factors $(n=18)$ and migraine histories prior to MR neurography

\begin{tabular}{|c|c|c|c|c|c|c|c|c|c|c|c|}
\hline \multicolumn{2}{|c|}{ Age (yr) } & \multicolumn{2}{|c|}{ Sex } & \multicolumn{2}{|c|}{$\begin{array}{l}\text { Migraine } \\
\text { Frequency }^{\mathrm{a}}\end{array}$} & \multicolumn{2}{|c|}{$\begin{array}{l}\text { Migraine } \\
\text { Laterality }\end{array}$} & \multicolumn{2}{|c|}{$\begin{array}{c}\text { Positive } \\
\text { Family History }\end{array}$} & \multicolumn{2}{|c|}{$\begin{array}{c}\text { Previous } \\
\text { Head Trauma }\end{array}$} \\
\hline $\begin{array}{l}\text { Younger } \\
\text { than } 40\end{array}$ & $\begin{array}{l}\text { Older } \\
\text { than } 40\end{array}$ & Male & Female & $<15$ per mo & $>15$ per mo & Left & Right & Yes & No & Yes & No \\
\hline $6(33 \%)$ & $12(67 \%)$ & $3(17 \%)$ & $15(83 \%)$ & $5(38 \%)$ & $8(62 \%)$ & $10(56 \%)$ & $8(44 \%)$ & $3(17 \%)$ & $15(83 \%)$ & $5(28 \%)$ & $13(72 \%)$ \\
\hline
\end{tabular}

${ }^{\mathrm{a}}$ Five patients were not reported.

Table 2: Migraine diagnostic and treatment modalities prior to acquisition of MR neurography

\begin{tabular}{|c|c|c|c|c|c|c|c|c|c|}
\hline \multicolumn{2}{|c|}{ Botox } & \multicolumn{2}{|c|}{$\begin{array}{l}\text { Nerve } \\
\text { Block }\end{array}$} & \multicolumn{2}{|c|}{$\begin{array}{c}\text { Radiofrequency } \\
\text { Ablation }\end{array}$} & \multicolumn{2}{|c|}{$\begin{array}{l}\text { Previous } \\
\text { Operation }^{\mathrm{a}}\end{array}$} & \multicolumn{2}{|c|}{$\begin{array}{l}\text { Previous Head/ } \\
\text { Neck Imaging }\end{array}$} \\
\hline Yes & No & Yes & No & Yes & No & Yes & No & Yes & No \\
\hline $13(72 \%)$ & $5(28 \%)$ & $15(83 \%)$ & $3(17 \%)$ & $5(28 \%)$ & $13(72 \%)$ & $6(33 \%)$ & $12(67 \%)$ & $6(33 \%)$ & $12(67 \%$ \\
\hline
\end{tabular}

a Previous migraine operations included occipital nerve neurectomies or neurolysis.

${ }^{\mathrm{b}}$ All previous imaging was either standard 1.5T of the brain or cervical spine MRI or CT and evaluated as negative for pathology related to migraine symptoms.

\begin{tabular}{|c|c|c|c|}
\hline $\begin{array}{c}\text { MRN } \\
\text { Characteristic }\end{array}$ & Subject Group & Control Group & $P$ Value \\
\hline Diameter & $1.77 \pm 0.4$ & $1.29 \pm 0.25$ & .001 \\
\hline Signal & $269.06 \pm 170.93$ & $222.44 \pm 170.46$ & .043 \\
\hline SNR & $15.79 \pm 4.59$ & $14.02 \pm 5.23$ & .009 \\
\hline CNR & $2.57 \pm 4.89$ & $-1.26 \pm 5.02$ & .004 \\
\hline
\end{tabular}

${ }^{a}$ All values are mean $\pm S D$.

ing of the brain or cervical spine, and findings were unremarkable with respect to migraine etiology.

On the quantitative analysis of reader 1 , the mean GON diameter for the symptomatic side was significantly greater $(1.77 \mathrm{~mm})$ than that on the asymptomatic side $(1.29 \mathrm{~mm})(P=.001$; Table 3 and Figs 4 and 5). In addition, the difference of GON signal intensity between the symptomatic and asymptomatic sides was statistically significant at 269.06 versus 222.44 , respectively ( $P=$ .043; Table 3). The calculated SNRs of the GON on the symptomatic side were notably higher at 15.79 compared with those on the asymptomatic side at $14.02(P=.009$; Table 3$)$. Furthermore, the calculated CNRs of the GON relative to the ipsilateral semispinalis capitis muscle were significantly higher and more positive on the symptomatic side than on the asymptomatic side at 2.57 and $-1.26(P=.004$; Table 3$)$.

Intra- and interobserver statistical analysis with the intraclass correlation coefficient demonstrated fair-to-excellent interobserver and intraobserver performance (ICC > 0.54) in all 4 parameters (nerve diameter, nerve signal, SNR, and CNR), including excellent performance when analyzing the nerve diameter (ICC, 0.81-0.93; Table 4). Furthermore, no statistically significant correlation was found between the duration of migraine symptoms (defined as the length of time between onset and MRN acquisition) and the GON diameter (Spearman rank correlation coefficient, $0.21 ; P=.4$ ), and only a moderate negative correlation was found between the duration of symptoms and the GON signal (Spearman rank correlation coefficient, $-0.499 ; P=.351$ ) (Fig 6). The mean duration of migraine symptoms in this cohort of 18 patients was $3415 \pm 3127$ days (approximately 9 years).

\section{DISCUSSION}

Migraine headaches present a challenge to health care providers because they have a spectrum of symptoms and are often difficult to manage. While new evidence emerges about the etiology and pathophysiology of chronic migraines, many uncertainties remain. Currently, the diagnostic strategy is limited and is based on clinical findings and blinded or targeted perineural injections. ${ }^{31}$ This study establishes that a noninvasive technique, MRN, can be used to evaluate the greater occipital nerve in such cases.

Among our cohort of 18 patients, a statistically significant difference was observed with respect to the GON diameter and signal intensity alterations, both being higher on the symptomatic side and thus consistent with the previous literature citing qualitative differences. ${ }^{35,36}$ Furthermore, the SNR of the GON was significantly higher on the symptomatic side, suggesting greater resolution of the nerve versus surrounding noise and the ability to detect differences in normal peripheral nerve anatomy versus pathology. The CNR, the difference in SNR between 2 relevant tissue types, was significantly higher and a more positive value on the symptomatic side than the asymptomatic side. This finding suggests more signal activation from the nerve than from background noise of muscle on the symptomatic side. ${ }^{42}$ In most cases, when there was a discrepancy between MRN findings and the clinical laterality of pain, confounding factors such as pathology on the other side may have produced discrepant results. The CNR showed a relatively lower ICC. Thus, SNR seems to be the more useful parameter in predicting the symptomatic side in these subjects with complex migraines. The variability may have resulted from different locations of ROIs in the muscle, while neural abnormality was more apparent on 3D imaging.

As medical innovation and technology continue to evolve, ${ }^{39}$ the potential use of MRN in the future as a targeted approach to treatment planning in patients with migraine seems promising. An objective demonstration of neural abnormality has the potential to guide treatment and improve outcomes. The current standard of care is based on clinical history, physical examination including point tenderness of the GON, and response to nerve block and Botox in that location. However, if patients do not respond to injections, documentation of a normal or pathologic GON by MRN can help the treating physician choose the most suitable treatment plan for that individual. MRN is also useful in depicting the nerve abnormality proximal to the entrapment 

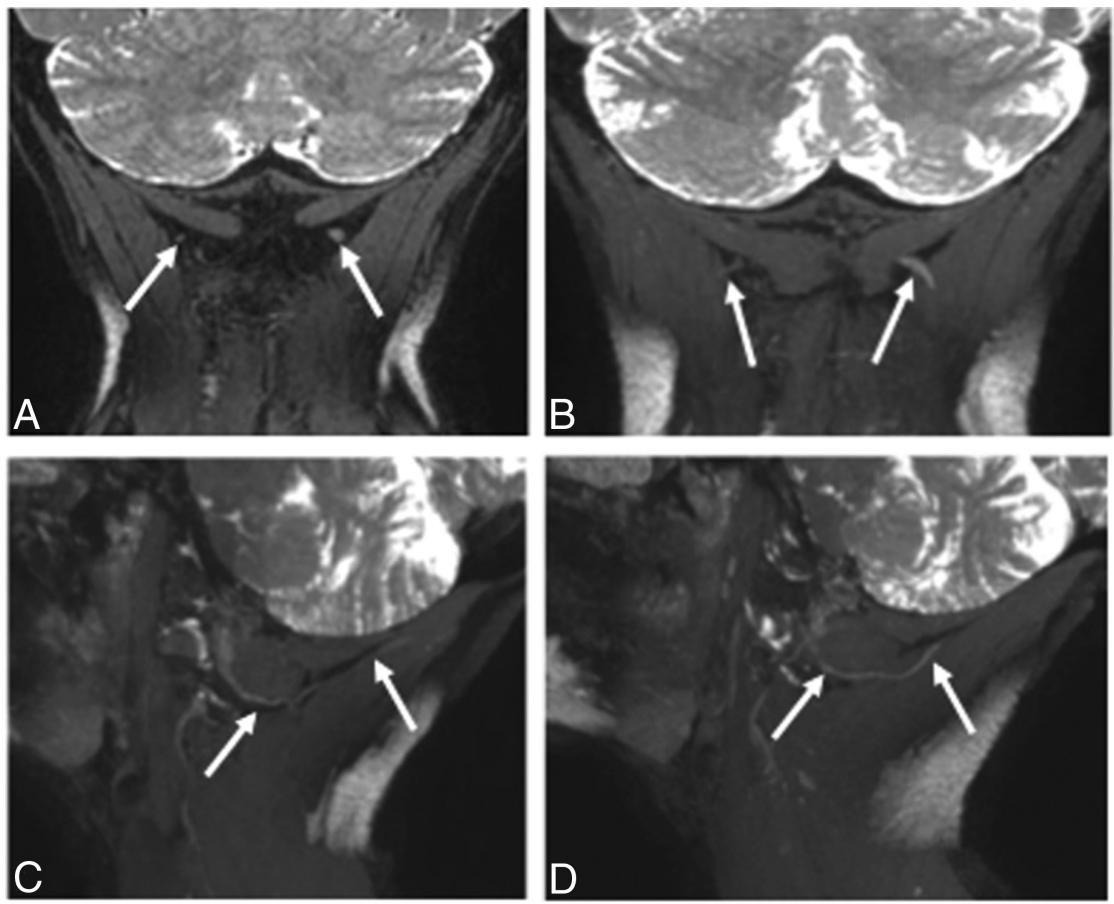

FIG 4. $3 T$ MRN demonstrating left GON neuropathy in a 62-year-old woman with left occipital neuralgia. $A$ and $B$, Coronal 3D PSIF and 8-mm-thick MIP reconstruction show an asymmetrically thickened and hyperintense left GON (arrows). $C$ and D, Eight-millimeter-thick isotropic MIP reconstruction in the sagittal planes. Note the normal right GON (arrows in $C$ ) and abnormal left GON (arrows in $D$ ) with increasing thickening proximal to the muscle entrapment site.
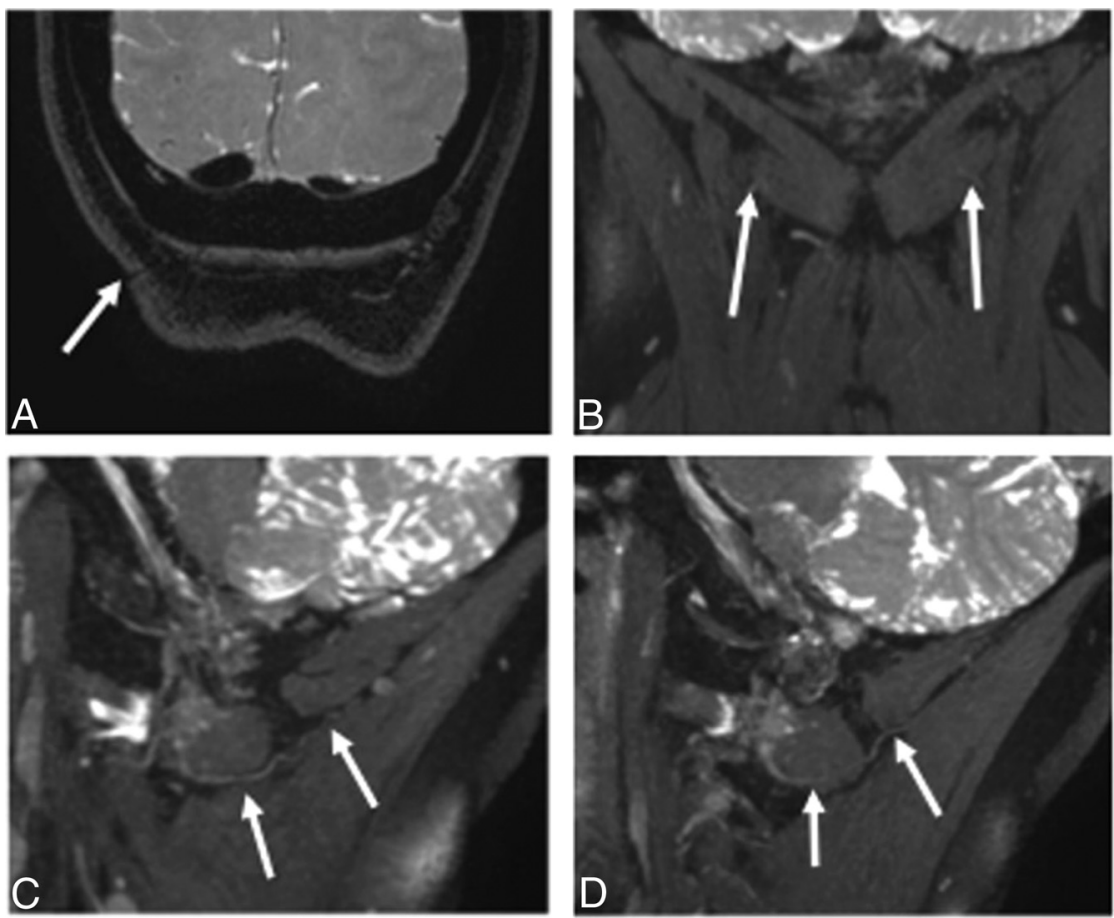

FIG 5. 3T MRN demonstrating persistent right GON neuropathy in a 55-year-old woman with prior right occipital neurolysis and persistent right occipital neuralgia. $A$, Coronal 3D PSIF shows the surgical scar site (arrow). B, A more anterior coronal image shows minimal hyperintensity of the right GON (arrows). C and D, Eight-millimeter-thick isotropic MIP reconstruction in the sagittal planes. Note the normal persistently hyperintense right GON (arrows in $C$ ) and normal left GON (arrows in D). site. Therefore, the technique could show persistent abnormality, despite prior neurolysis (Fig 5).

The limitations of our study include the small sample size. However, the radiologists were blinded to the laterality of symptoms, and each of these patients served as his or her own control, given unilateral GON migraine symptoms, making these initial observations valuable. This value is reflected by fair-toexcellent ICCs. We have also considered that previous perineural injection and Botox injections, radiofrequency ablation, and surgical procedures could impact the appearance of the nerve on imaging. Our chart review revealed limited documentation of specific previous treatments performed by other health care providers before presenting to our institution, including frequency, dates, method, and location. However, the patients were imaged for persistent symptoms of unilateral occipital neuralgia. We did not evaluate other imaging sequences performed as part of an occipital neuralgia protocol because they were used to rule out any central lesion at the base of the brain or incidental spinal or neck lesion that could contribute to symptoms.

Further limitations of this study are due to restrictions in current medical technology. The strength of the magnetic field used in this study varied, with 7 (39\%) patients undergoing the newer $3 \mathrm{~T}$ MR imaging versus 11 (61\%) patients undergoing $1.5 \mathrm{~T}$ MR imaging. While the difference in $1.5 \mathrm{~T}$ and $3 \mathrm{~T}$ MRN can be significant and may make data nonhomogeneous and thus more difficult to analyze and compare, our investigation is nevertheless a pilot study, validating the use of multiple scanners. On 3T MR imaging technology, the SNR is usually superior, with improved resolution of images. Thus, in addition to the SNR, nerve diameter and CNR were also evaluated. Finally, both sides were compared in all cases to mitigate the effects of individual scans because symptomatic GON measurements were compared with the contralateral asymptomatic GON measurements within the same MRN image and not compared with measurements obtained among different images.

In the future, we hope to both increase the study sample and expand the 
Table 4: Intra- and interobserver statistical analysis showing inter- and intraobserver performance among all 4 parameters using ICCs

\begin{tabular}{lc}
\hline & ICC \\
\hline Reader 1 (initial) versus reader 1 (4 mo later) & \\
Nerve diameter (mm) & 0.93 \\
Nerve signal & 0.79 \\
SNR & 0.74 \\
CNR & 0.68 \\
Reader 1 versus reader 2 & \\
Nerve diameter (mm) & 0.81 \\
Nerve signal & 0.71 \\
SNR & 0.67 \\
CNR & 0.54 \\
\hline
\end{tabular}

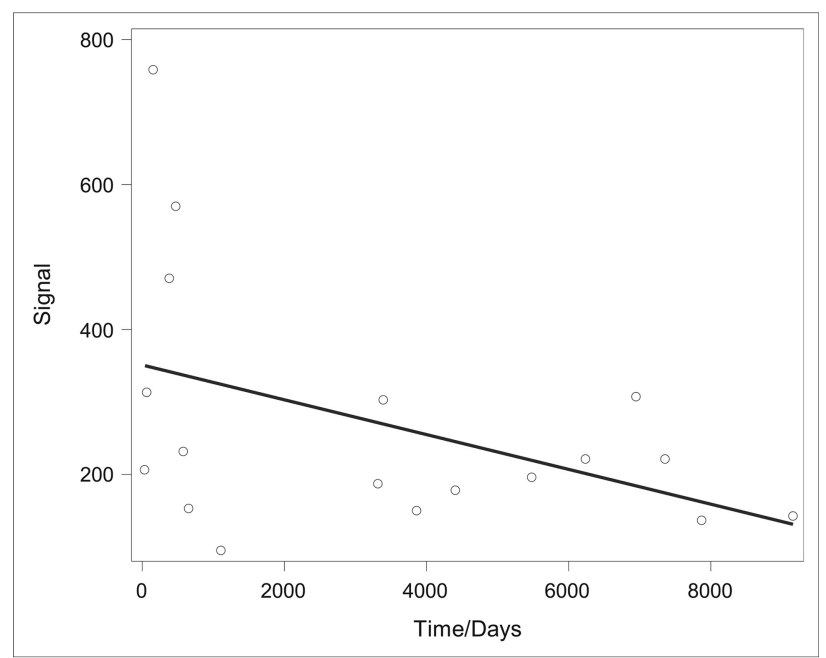

FIG 6. Evaluation of the correlation between the duration of migraine symptoms (defined as length of "time" in days from symptom onset to MRN acquisition) and the GON signal yielded a Spearman rank correlation coefficient of -0.499 with $P=.351$. When we compared the duration of symptoms and the GON diameter using the same statistical methodology, no significant correlation was found (Spearman rank correlation, $0.21 ; P=.4$ ). The mean duration of migraine symptoms in this cohort of 18 patients was $3415 \pm 3127$ days (approximately 9 years).

scope of this study to include previously nontreated patients and other migraine trigger sites, including the frontal, temporal, and nasoseptal regions. As diagnostic imaging continues to evolve and methodologies of image acquisition are improved, we hope that MRN will help provide individualized care to patients with migraines.

\section{CONCLUSIONS}

In patients with unilateral clinical signs of GON compression, quantitative evaluation of the GON on MRN reveals different imaging appearances of the affected-versus-nonaffected nerves. In the future, the study can be expanded to include larger cohorts and other peripheral nerve disorders.

Disclosures: Avneesh Chhabra—UNRELATED: Consultancy: Icon Medical; Royalties: Jaypee Wolters.

\section{REFERENCES}

1. Stewart WF, Simon D, Shechter A, et al. Population variation in migraine prevalence: a meta-analysis. J Clin Epidemiol 1995;48: 269-80 CrossRef Medline
2. Merikangas KR. Contributions of epidemiology to our understanding of migraine. Headache 2013;53:230-46 CrossRef Medline

3. Edmeads J, Mackell JA. The economic impact of migraine: an analysis of direct and indirect costs. Headache 2002;42:501-09 CrossRef Medline

4. Lipton RR, Stewart WF, Diamond S, et al. Prevalence and burden of migraine in the United States: data from the American Migraine Study II. Headache 2001;41:646-57 CrossRef Medline

5. Leonardi M, Steiner TJ, Scher AT, et al. The global burden of migraine: measuring disability in headache disorders with WHO's Classification of Functioning, Disability and Health (ICF). J Headache Pain 2005;6:429-40 CrossRef Medline

6. Moskowitz MA, Nozaki K, Kraig RP. Neocortical spreading depression provokes the expression of c-fos protein-like immunoreactivity within trigeminal nucleus caudalis via trigeminovascular mechanisms. J Neurosci 1993;13:1167-77 Medline

7. Bolay $H$, Reuter $U$, Dunn $A K$, et al. Intrinsic brain activity triggers trigeminal meningeal afferents in a migraine model. Nat Med 2002; 8:136-42 CrossRef Medline

8. Ambrosini A, D'Alessio C, Magis D, et al. Targeting pericranial nerve branches to treat migraine: current approaches and perspectives. Cephalalgia 2015;35:1308-22 CrossRef Medline

9. Schueler M, Messlinger K, Dux M, et al. Extracranial projections of meningeal afferents and their impact on meningeal nociception and headache. Pain 2013;154:1622-31 CrossRef Medline

10. Schueler M, Neuhuber WL, De Col R, et al. Innervation of rat and human dura mater and pericranial tissues in the parieto-temporal region by meningeal afferents. Headache 2014;54:996-1009 CrossRef Medline

11. Guyuron B, Varghai A, Michelow BJ, et al. Corrugator supercilii muscle resection and migraine headaches. Plast Reconstr Surg 2000; 106:429-34; discussion 435-37 CrossRef Medline

12. Guyuron B, Tucker T, Davis J. Surgical treatment of migraine headaches. Plast Reconstr Surg 2002;109:2183-89 CrossRef Medline

13. Dirnberger F, Becker K. Surgical treatment of migraine headaches by corrugator muscle resection. Plast Reconstr Surg 2004;114:65257; discussion 658-59 CrossRef Medline

14. Guyuron B, Kriegler JS, Davis J, et al. Comprehensive surgical treatment of migraine headaches. Plast Reconstr Surg 2005;115:1-9 Medline

15. Poggi JT, Grizzell BE, Helmer SD. Confirmation of surgical decompression to relieve migraine headaches. Plast Reconstr Surg 2008; 122:115-22; discussion 123-24 CrossRef Medline

16. Guyuron B, Reed D, Kriegler JS, et al. A placebo-controlled surgical trial of the treatment of migraine headaches. Plast Reconstr Surg 2009;124:461-68 CrossRef Medline

17. Guyuron B, Kriegler JS, Davis J, et al. Five-year outcome of surgical treatment of migraine headaches. Plast Reconstr Surg 2011;127: 603-08 CrossRef Medline

18. Janis JE, Barker JC, Javadi C, et al. A review of current evidence in the surgical treatment of migraine headaches. Plast Reconstr Surg 2014; 134(4 suppl 2):131S-41S CrossRef Medline

19. Ducic I, Hartmann EC, Larson EE. Indications and outcomes for surgical treatment of patients with chronic migraine headaches caused by occipital neuralgia. Plast Reconstr Surg 2009;123:1453-61 CrossRef Medline

20. Caputi CA, Firetto V. Therapeutic blockade of greater occipital and supraorbital nerves in migraine patients. Headache 1997;37:174-79 CrossRef Medline

21. Dach F, Éckeli AL, Ferreira Kdos S, et al. Nerve block for the treatment of headaches and cranial neuralgias: a practical approach. Headache 2015;55(suppl 1):59-71 CrossRef Medline

22. Dilli E, Halker R, Vargas B, et al. Occipital nerve block for the shortterm preventive treatment of migraine: a randomized, doubleblinded, placebo-controlled study. Cephalalgia 2015;35:959-68 CrossRef Medline

23. Singh M, Rios Diaz AJ, Gobble R, et al. Causal relation between nerve compression and migraine symptoms and the therapeutic role of 
surgical decompression. Plast Reconstr Surg Glob Open 2015;3:e395 CrossRef Medline

24. Palamar D, Uluduz D, Saip S, et al. Ultrasound-guided greater occipital nerve block: an efficient technique in chronic refractory migraine without aura? Pain Physician 2015;18:153-62 Medline

25. Inan LE, Inan N, Karadaş, et al. Greater occipital nerve blockade for the treatment of chronic migraine: a randomized, multicenter, double-blind, and placebo-controlled study. Acta Neurol Scan 2015; 132:270-77 CrossRef Medline

26. Becker D, Amirlak B. Beyond beauty: onobotulinumtoxin A (Botox $\left.^{\circledR}\right)$ and the management of migraine headaches. Anesthes Pain Med 2012;2:5-11 CrossRef Medline

27. Janis JE, Dhanik A, Howard JH. Validation of the peripheral trigger point theory of migraine headaches: single-surgeon experience using botulinum toxin and surgical decompression. Plast Reconstr Surg 2011;128:123-31 CrossRef Medline

28. Sanniec K, Borsting E, Amirlak B. Decompression-avulsion of the auriculotemporal nerve for treatment of migraines and chronicheadaches. Plast Reconstr Surg Glob Open 2016;4:e678 CrossRef Medline

29. Amirlak B, Sanniec K, Pezeshk R, et al. Anatomical Regional Targeted (ART) Botox injection technique: a novel paradigm for migraines and chronic headaches. Plast Reconstr Surg Glob Open 2016; 4:e1194 CrossRef Medline

30. Mosser SW, Guyuron B, Janis JE, et al. The anatomy of the greater occipital nerve: implications for the etiology of migraine headaches. Plast Reconstr Surg 2004;113:693-97; discussion 698-700 CrossRef Medline

31. VanderHoek MD, Hoang HT, Goff B. Ultrasound-guided greater occipital nerve blocks and pulsed radiofrequency ablation for diagnosis and treatment of occipital neuralgia. Anesthes Pain Med 2013; 3:256-59 CrossRef Medline

32. Grant GA, Goodkin R, Maravilla KR, et al. MR neurography: diagnostic utility in the surgical treatment of peripheral nerve disorders. Neuroimaging Clin N Am 2004;14:115-33 CrossRef Medline
33. Fisher S, Wadhwa V, Manthuruthil C, et al. Clinical impact of magnetic resonance neurography in patients with brachial plexus neuropathies. Br J Radiol 2016;89:20160503 CrossRef Medline

34. Vargas MI, Viallon M, Nguyen D, et al. New approaches in imaging of the brachial plexus. Eur J Radiol 2010;74:403-10 CrossRef Medline

35. Wang X, Harrison C, Mariappan YK, et al. MR neurography of brachial plexus at 3.0 $\mathrm{T}$ with robust fat and blood suppression. Radiology 2017;283:538-46 CrossRef Medline

36. Chhabra A, Subhawong TK, Bizzell C, et al. 3T MR neurography using three-dimensional diffusion-weighted PSIF: technical issues and advantages. Skeletal Radiol 2011;40:1355-60 CrossRef Medline

37. Zhang Z, Meng Q, Chen $Y$, et al. 3-T imaging of the cranial nerves using three-dimensional reversed FISP with diffusion-weighted MR sequence. J Magn Reson Imaging 2008;27:454-58 CrossRef Medline

38. Cox B, Zuniga JR, Panchal N, et al. Magnetic resonance neurography in the management of peripheral trigeminal neuropathy: experience in a tertiary care centre. Eur Radiol 2016;26:3392-400 CrossRef Medline

39. Zhang Z, Song L, Meng Q, et al. Morphological analysis in patients with sciatica: a magnetic resonance imaging study using three-dimensional high-resolution diffusion-weighted magnetic resonance neurography techniques. Spine 2009;34:E245-50 CrossRef Medline

40. Parrish TB, Gitelman DR, LaBar KS, et al. Impact of signal-to-noise on functional MRI. Magn Reson Med 2000;44:925-32 Medline

41. Redpath T. Signal-to-noise ratio in MRI. Br J Radiol 1998:71:704-07 CrossRef Medline

42. Welvaert $M$, Rosseel $Y$. On the definition of signal-to-noise ratio and contrast-to-noise ratio for fMRI data. PLoS One 2013;8:e77089 CrossRef Medline

43. Hallgren K. Computing inter-rater reliability for observational data: an overview and tutorial. Tutor Quant Methods Psychol 2012;8: 23-34 CrossRef Medline 